\title{
Forced Leadership as a Social Psychological Phenomenon in Professionally Successful Women Scientists
}

\author{
Cherepiekhina Olha ${ }^{1, *}$, Dysa Olena ${ }^{2}$, Bulanov Valerii ${ }^{3}$, Turubarova Anastasiia ${ }^{4}$ and \\ Rukolyanska Nataliya ${ }^{5}$
}

\author{
${ }^{1}$ Department of Psychology and Pedagogy, Oles Honchar Dnipro National University, Dnipro, Ukraine \\ ${ }^{2}$ Department of Pedagogical and Age Psychology, Oles Honchar Dnipro National University, Dnipro, Ukraine \\ ${ }^{3}$ Department of Practical Psychology, Classical Private University, Zaporizhzhya, Ukraine \\ ${ }^{4}$ Department of Special Pedagogy and Special Psychology, Municipal Institution of Higher Education \\ "Khortytsia National Training and Rehabilitation Academy" of Zaporizhia Regional Council, Zaporizhzhya, \\ Ukraine \\ ${ }^{5}$ Department of Social and Humanitarian Disciplines, Municipal Institution of Higher Education "Khortytsia \\ National Training and Rehabilitation Academy" of Zaporizhia Regional Council, Zaporizhzhya, Ukraine
}

\begin{abstract}
In today's world, women are increasingly taking the place of leaders, so they have to be active, focused, resistant to stress, have a high level of self-regulation, and be able to work in a team. So, we can see how women are sometimes forced to become leaders in difficult life circumstances. Due to persistence, self-education, determination, they work in leadership positions and demonstrate masculine personality traits. The study aimed to study the psychological characteristics of women scientists who hold high positions in educational establishments - vice-rector, dean, and department head. We hypothesized that the professional success of women scientists depends on the level of their potential leadership skills. The study involved 75 women from higher education institutions who successfully work as vice-rectors, deans, heads of departments. All of them have the degree of doctors of philosophy from various scientific fields and combined scientific activity with managerial activity. Analysis of the results of empirical research showed that a high level of leadership skills determines the professional success of $37 \%$ of women studied, but $63 \%$ of women scientists have other determinants of professional success. Differences in indicators were identified, and three groups of women were characterized depending on the level of development of their leadership abilities. In groups of women with a medium and low level of leadership skills, the main determinants of professional success are the focus on real-life circumstances, high level of development of stable emotional and volitional sphere, voluntary self-regulation, self-control in difficult situations, emotional stability. Women who have achieved professional success, not on the basis of potential leadership abilities, form a socially determined personal quality - forced leadership, which we tend to consider as a social psychological phenomenon, which is based on the ability to adapt to living conditions in situations requiring a person to choose against own individual psychological features, namely to become a leader, to cultivate the traits inherent in a true leader.
\end{abstract}

Keywords: Leadership, professionally successful women, women scientists, women's leadership, professionally successful women.

\section{INTRODUCTION}

In the 21 st century, there is still a significant gap in the representation of women in high-level management positions in all major industries, indicating a wide range of issues that need to be explored. However, this does not apply to women scientists who have been active and in leadership positions for a relatively long time. The mental well-being of professionally successful women scientists affects their physical health and, accordingly, the quality of their management decisions. As a result, the effectiveness of higher education, the conduct of scientific research in the industry of countries is determined, among other things, by the

\footnotetext{
*Address correspondence to this author at the Department of Psychology and Pedagogy, Oles Honchar Dnipro National University, Prospekt Dmitry Yavornitsky, 35, Faculty of Psychology and Special Education, Office 52, Dnipro 49000, Ukraine; Tel: +380505318737;
}

E-mail: olga.cherry.2013@gmail.com emotional state of women scientists. Our study of the forced leadership phenomenon in these women opens up opportunities for improving the education and science industry by,

- $\quad$ understanding the determinants of the success of women scientists in leadership positions;

- understanding the personality traits that determine the professional success of women scientists with different levels of leadership skills.

In modern international society, a woman occupies a rather important position. She does not deny the power, logic, pragmatism that men have. Still, she is ready to demonstrate such qualities; as a result, the boundaries between gender characteristics begin to blur. Traditionally, leadership has been studied almost without regard to gender, as the lead role was 
considered purely male. Current areas of gender research cover a variety of issues. Leadership was mostly studied in business groups or groups with intimate relationships (family, lovers). Proponents of Freudianism have traditionally shown a negative attitude toward women's leadership. Women leaders were considered to have unhealthy gender identities. Their desire for leadership, which they called "phallic," was seen as a manifestation of the inferiority of a woman who envied men.

Women are increasingly taking the place of leaders. Still, successful leadership is forced to show activity, determination, resilience, strong-willed self-regulation, and the ability to work in a team. More and more support programs for women leaders, leadership development training, leadership skills, and various electives and research on this topic are being introduced [1-4]. We can see how women are sometimes forced to become leaders in difficult life circumstances in today's world. Due to self-education, purposefulness, they work in leadership positions and demonstrate masculine personality traits. In the late $20^{\text {th }}$ century, professionally successful women's leadership problems began to be actively studied. Some psychological aspects were investigated, particularly the neurotic dependence of successful women [5], the phenomenon of the impostor in highranking women [6].

The emergence of a large number of women in leadership positions in organizations and the rapid growth of their role in society quickly attracted the attention of researchers. There is a growing perception that women can play a leading role. In today's world society, the percentage of women entrepreneurs is increasing. Since 2000, the participation of women in entrepreneurship has been growing internationally. According to the Global Entrepreneurship Report on Women Entrepreneurs, the Total Women's Entrepreneurship Activity Index (TEA) ranges from $39.1 \%$ in Peru to $1.2 \%$ in Japan [7]. In 2019, the share of women in senior management positions worldwide increased to $29 \%$, the highest number ever recorded. In 2020 , this percentage remained unchanged. $87 \%$ of global mid-market companies have at least one woman at the top management level in 2020 [8].

It should be noted that the first studies of gender aspects of leadership were conducted in the United States. Active gender psychology of leadership, as a scientific field of Western psychology, began to develop in the 70 s of the 20th century. Its development took place under the influence of feminist psychology at the crossroads of social psychology, psychology of gender differences, psychology of women, social psychology of relations between the sexes-the main representatives of this area - J. Rosener, E. Eagle, S. Bjorn, J. Gorsted.

Although researchers have encountered significant difficulties in compiling a short, consistent list of key traits common to all leaders, in recent years, many scholars have concluded that leaders are indeed different from other people in certain psychological positions. Beron and co-authors, considering the problem of key traits of leaders, note that leaders are ahead of other people in such characteristics as,

\section{- $\quad$ perseverance}

- the desire to succeed combined with great energy and determination; arrogance; art; leadership motivation

- $\quad$ the desire to control and have power over other people.

Among the characteristics of thinking inherent in leaders, the authors note flexibility, productivity, speed, and analytical skills [9].

Much of the existing research focuses on the challenges faced by women leaders in higher education that are,

- $\quad$ the problem of authentic leadership of women with colored skin [10],

- cultural and structural elements of higher education institutions [11],

- ways to achieve leadership with different identities [12].

However, even though the phenomenon of female leadership is widely represented in scientific research of women scientists, forced leadership as a social psychological phenomenon in professionally successful women scientists was not the subject of special scientific research.

Based on the experience of studying women leaders [13-16], in the reference sources, there are some suggestions for the development of leadership skills and career advancement:

1. Formulate a set of personal values to achieve leadership goals. 
2. Be authentic, which means to be true to yourself, your values, and ethics, be honest and open.

3. Be able to adapt, i.e., maintain cognitive flexibility, adapt leadership behavior to the context of the activity.

4. Have a support network - discuss obstacles and challenges along the way.

5. Take responsibility and be resilient.

6. Identify issues related to change and create a group of leaders for the joint process.

However, despite such systemic studies in modern science, the phenomenon forced leadership of professionally successful women scientists was not the subject of special scientific research.

The purpose of this paper is to highlight the results of an empirical study of the psychological characteristics of professionally successful women scholars and determine the role of leadership and other socio-psychological factors in the process of their professional growth. The subject of the study was leadership skills as the basis of the professional success of women scientists. Still, we assume that not all women leaders have high potential leadership skills. So, in this article, we bind the professional success of women scientists to their careers in educational institutions.

\section{METHODS}

To achieve the goal and confirm the hypothesis, we conducted an experimental study. The study aimed to identify personality traits that determine women's professional success with different levels of leadership skills. The planned study looked at the level of leadership skills in professionally successful women and the relationship between leadership, success, and other personal characteristics.

The study was conducted from January 2021 to March 2021. Based on a theoretical analysis of the reference materials on the problems of success and the psychology of women's leadership, we have identified the criteria for a professionally successful woman, according to which we selected women scientists for empirical research:

1. availability of career growth;

2. systematic self-development;
3. subjective recognition of own success;

4. financial independence.

To conduct an empirical study, 128 successful (in our opinion) women aged 32 to 55 years were interviewed, of which 96 were married and 32 were single. Women selected for the survey had a fairly high professional status, career growth, satisfaction with their work, salary, social status, constant engagement in self-development. They represented higher educational establishments of Ukraine, who successfully worked as vice-rectors, deans, and heads of departments. They all had the degree of Doctor of Philosophy in various scientific fields and combined academic activity with managerial work. Women leaders of the Oles Honchar Dnipro National University have participated in the study. The study was conducted in the framework of the cathedral scientific theme of Oles Honchar Dnipro National University of research work "Features of the detection of the image of" I "in the context of lifelong learning." Registration number 0119U100595, date of registration 13.02.2019.

Standardized psychological techniques were used in the research to study leadership abilities and identify the personality traits of women scientists.

\section{Test-Questionnaire "Self-Assessment of Leadership" (Fetiskin, Kozlov, Manuilov)}

The test consists of 10 questions, each of which assumes an affirmative or negative answer. Data processing involves counting the number of responses "a" and "b". Thus, the methodology allows you to identify high, medium, or low-level manifestations of leadership skills in joint activities.

\section{Methodology "Diagnosis of Leadership Skills" (Zharikov, Krushelnytsky)}

The purpose of the methodology is to identify the level of leadership abilities. The subject is offered 50 statements, which are required to answer "yes" or "no". There is no average value in the answers. The score for the answers is calculated using the key to the questionnaire. The interpretation of the test results is to correlate the scores obtained with the key. If the sum of the points turned out to be less than 25 , then the leader's qualities are weakly expressed. If the sum of points is in the range from 26 to 35 , then the leader's qualities are expressed in an average way. If the sum of points was from 36 to 40 , then leadership qualities are strongly expressed. If the total of points is more 
than 40 , then this person, as a leader, is inclined to dictate.

\section{Methodology "Diagnosis of Personality for Motivation to Succeed" (Ehlers)}

When diagnosing a personality to identify the motivation for success, Ehlers proceeded from the position: a person whose motivation for success predominates prefers a medium or low level of risk. She tends to avoid high risk. With strong motivation for success, hopes for success are usually more modest than weak motivation for success, but such people work hard to achieve success and strive for success. J. Atkinson, H. Heckhausen et al. Demonstrated that there are at least three fundamental motivational vectors that decisively determine the nature of the interdependence of activity and achievement motivation: individual subjective ideas about the likelihood of personal success and the complexity of the task facing the individual, the degree of significance for the subject of this task and, in this regard, the strength of the desire to maintain and improve selfesteem; the tendency of this particular person to describe to himself adequately, other people and circumstances of responsibility for success and failure. From the point of view of $D$. McClelland, achievement motivation can develop in adulthood, first of all, through learning. As L. Jewell emphasizes, "in addition, it can develop in the context of work, when people directly experience all the benefits associated with achievement." Adequate motivation for achievement can be naturally formed and constructively implemented only within the framework of a system of relations characterized by genuine cooperation. Above all, a harmonious combination of personally nondestructive pressure: positive authorization for success and non-humiliating support in case of failure. The Ehlers test contains 41 questions, each of which must be answered "yes" or "no". The technique allows you to identify low, medium, moderately high, and very high motivation levels for success.

\section{Questionnaire "Study of Volitional Self- Regulation" (Eidman)}

Purpose of the study: to determine the level of development of volitional self-regulation. Research procedure. Using a test questionnaire, the study of volitional self-regulation is carried out either with one subject or with a group. To ensure the independence of the answers of the subjects, everyone receives the text of the questionnaire, an answer sheet, on which the numbers of the questions are printed, and next to them the column for the answer.

Instructions for the subject. You are offered a test containing 30 statements. Read each carefully and decide if this statement is true or false in relation to you. If it is true, then in the answer sheet, put a plus (+) sign next to the number of this statement, and if you think that it is wrong in relation to you, then a minus (-). The purpose of processing the results is to determine the values of volitional self-regulation indices by items of the general scale (B) and indices by subscales "persistence" $(\mathrm{H})$ and "self-control" (C).

Each index is the sum of points obtained when calculating the coincidence of the subject's answers with the general scale or subscale key. The questionnaire contains disguised statements. Therefore, the total score on the "B" scale should be in the range from 0 to 24 , on the "persistence" subscale from 0 to 16, and on the "self-control" subscale - from 0 to 13: The key for calculating the indices of volitional self-regulation. The levels of volitional self-regulation are determined in comparison with the average values of each of the scales. Suppose they make up more than half of the maximum possible amount of coincidences. In that case, this indicator reflects a high level of development of general self-regulation, perseverance, or self-control. For the "B" scale, this value is 12 , for the " $\mathrm{H}$ " scale - 8 , for the "C" scale - 6 .

\section{Methodology "Assessment of the Need for Approval" (Crown, Marlowe)}

The desire to earn praise, approval is one of the most significant human needs. The scale of motivation for approval, developed by American psychologists Douglas Crown and David Marlowe, serves to identify this need. It allows us to determine an indirect measure of a person's need for the approval of others. The higher this need, the more the subject's behavior corresponds to the approved pattern. Such people do not mind uninteresting work, restrain their aggressive reactions.

On the whole, they are more conformable, susceptible to social influences. The test is a collection of 20 statements. If the statement coincides with personal opinion, then it is proposed to answer "yes"; if it does not match, then answer "no". The answer for each position is estimated at 1 point. Points are assigned only for the answer "yes" for the following positions: $1-5,8,11,14-16,20$, and only for the answer 
"no" for positions $6,7,9,10,12,13,17-19 \ldots$ The overall total for the need for approval is obtained by adding all the scores received. The higher it is, the greater the need for approval. It shows the degree of the subject's dependence on favorable evaluations from other people and his vulnerability and sensitivity to interpersonal and environmental influences. A high indicator reflects the usual style of reaction and the peculiarities of the subject's expectations in a situation of assessment by others. A low total indicator indicates that the subject's own beliefs are more valuable and his independence from the group. He is conflicted and not amenable to social influence, does not seek to resemble a model.

\section{Test-Questionnaire Purpose-in-Life Test (PIL) Kramb, Maholik, Adaptation by Leontiev}

The Purpose-in-Life Test (PIL) is an adapted version of the Purpose-in-Life Test (PIL) by James Crumbaugh and Leonard Maholick. The method was developed by the authors on the basis of Viktor Frankl's theory of the pursuit of meaning and logotherapy and pursued the goal of empirical validation of a number of representations of this theory, in particular, ideas about the existential vacuum and noogenic neuroses. The essence of these ideas is that failure in a person's search for the meaning of his life (existential frustration) and the resulting feeling of loss of meaning (existential vacuum) are the cause of a special class of mental illnesses - noogenic neuroses, which differ from the previously described types of neuroses. Initially, the authors sought to show that a) the technique measures the degree of "existential vacuum" in Frankl's terms precisely; b) the latter is characteristic of the mentally ill, and c) it is not simply identical with mental pathology. The "purpose in life", which the methodology diagnoses, is defined by the authors as an individual's experience of the ontological significance of life.

The subject is offered pairs of opposite statements. His task is to choose one of the two statements, which, in your opinion, is more true, and mark one of the numbers 1, 2, 3, depending on how confident you are in the choice (or 0 , if both statements in your opinion are the same are correct). Psychodiagnostics according to selected methods was performed individually and in some cases online. The diagnostics interviewed women scientists about their own attitudes toward success and the importance of leadership in women's careers. In individual testing, the interaction with the respondents was very important because we received more candid answers and more accurate results. As a result, we get indicators on 5 scales.

1. Goals in life. Scores on this scale characterize the presence or absence of goals in the subject's life in the future, which give life meaning, focus, and time perspective. Low scores on this scale, even with an overall high level of coolant, will be inherent in a person living today or yesterday. At the same time, high scores on this scale can characterize not only a purposeful person but also a projector whose plans have no real support in the present and are not supported by personal responsibility for their implementation. These two cases are easy to distinguish, given the indicators on other scales of LSS.

2. The process of life, or interest and emotional richness of life. The content of this scale coincides with the well-known theory that the only meaning of life is to live. This indicator indicates whether the subject perceives the very process of his life as interesting, emotionally rich, and full of meaning. High scores on this scale and low scores on the test will characterize the hedonist living today. Low scores on this scale are a sign of dissatisfaction with your life in the present; at the same time, however, it can be given a full meaning by memories of the past or focus on the future.

3. The effectiveness of life or satisfaction with selfrealization. The points on this scale reflect the assessment of the past part of life, the feeling of how productive and meaningful that part was lived. High scores on this scale and low scores on the rest will characterize a person living out his life, who has everything in the past, but the past can give meaning to the rest of his life. Low scores - dissatisfaction with the part of a life lived.

4. Locus of control-I (I am the master of life). High scores correspond to the idea of oneself as a strong personality with sufficient freedom of choice to build one's life following one's goals and ideas about its meaning. Low scores correspond to disbelief in their own abilities to control the events of their life.

5. Locus of control - life, or controllability of life. With high scores - the belief that a person is given control over his life freely makes decisions and implements them. Low scores - fatalism, the 
conviction that a person's life is not subject to conscious control, that freedom of choice is illusory, and it is pointless to think about anything for the future.

Research procedure especially for experimental study. In the first stage of the study, we developed a questionnaire to select professionally successful women, which contained several questions regarding job satisfaction and material security, career growth, self-development, etc. The survey method allowed us to fully select women who met the criteria of professional success, which we proposed based on a theoretical analysis of the scientific literature on success and leadership.

According to the survey results, 75 women were selected who met the specified criteria of professional success. The complexity of the study was that, first, women leaders always lack the time, and it was not always possible to agree with them on participation in the study immediately. Secondly, most women had to be interviewed, psychodiagnosis, and interviewed individually, which significantly increased the duration of the study - for two solid years.

At the beginning of the study, we suggested that depending on the leadership level, the indicators of personal characteristics of successful women may be different-correlation analysis allowed us to see differences in indicators and characterize each group of women. Analysis of the results of empirical research has shown that a high level of leadership skills really determines the professional success of women (37\%). But $63 \%$ have other determinants of professional success.

In the study, we used to cluster and correlation analysis. The obtained results of psychodiagnostics were analyzed and processed using the integrated software package SPSS 21. When performing mathematical and statistical calculations, the level of leadership skills was taken as an independent variable, determined by the methods of "Leadership SelfAssessment" and "Leadership Diagnostics". Dependent variables were all indicators obtained from the results of diagnostics by other methods.

\section{RESULTS}

We suggested that, depending on the leadership level, the personal characteristics of successful women scientists may be different-the use of cluster analysis allowed us to divide all subjects into three clusters (Table 1).

Table 1: The Results of Averages for the Three Cluster Groups

\begin{tabular}{|c|c|c|c|c|c|c|c|c|c|c|c|c|c|}
\hline 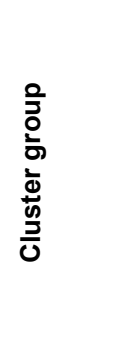 & 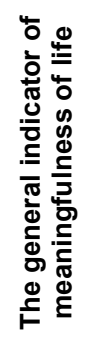 & $\begin{array}{l}\frac{\mathscr{0}}{\pi} \\
\stackrel{\square}{0} \\
\stackrel{\Xi}{\Xi}\end{array}$ & 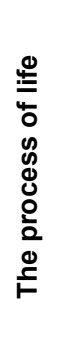 & 공 & 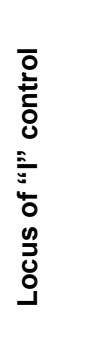 & 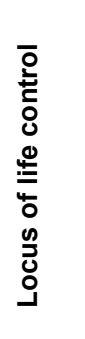 & 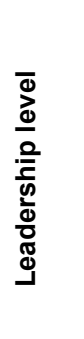 & 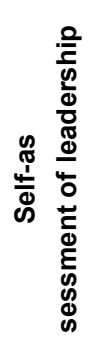 & 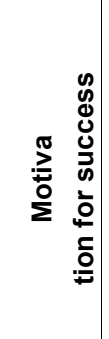 & 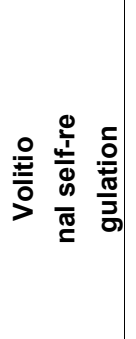 & 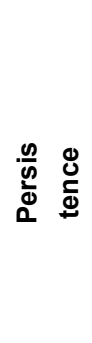 & 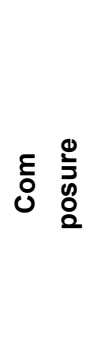 & 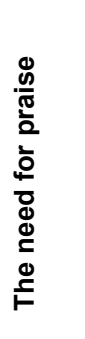 \\
\hline $\begin{array}{c}1 \text { 1st } \\
\text { cluster } \\
(n=27)\end{array}$ & 35.40 & 32.23 & 33.68 & 30.08 & 36.33 & 33.38 & 44.50 & 37.65 & 34.30 & 32.78 & 32.18 & 34.80 & 29.45 \\
\hline $\begin{array}{l}\text { 2nd } \\
\text { cluster } \\
(n=36)\end{array}$ & 23.69 & 23.40 & 22.06 & 25.63 & 21.79 & 25.79 & 21.50 & 26.00 & 24.35 & 22.90 & 25.02 & 20.65 & 26.19 \\
\hline $\begin{array}{c}\text { 3rd } \\
\text { cluster } \\
(n=12)\end{array}$ & 20.13 & 29.00 & 29.75 & 27.13 & 24.00 & 18.38 & 4.50 & 7.00 & 20.75 & 29.25 & 23.88 & 31.50 & 26.88 \\
\hline
\end{tabular}


According to the results of the cluster analysis, three groups of professionally successful women were singled out that are,

- $\quad$ first cluster included women with a high level of leadership skills - 27 women (37\%);

- $\quad$ second cluster included women with an average level of leadership qualities - 36 women $(48 \%)$;

- $\quad$ the third cluster included women having a low level of leadership skills - 12 women (15\%) (Figure 1).

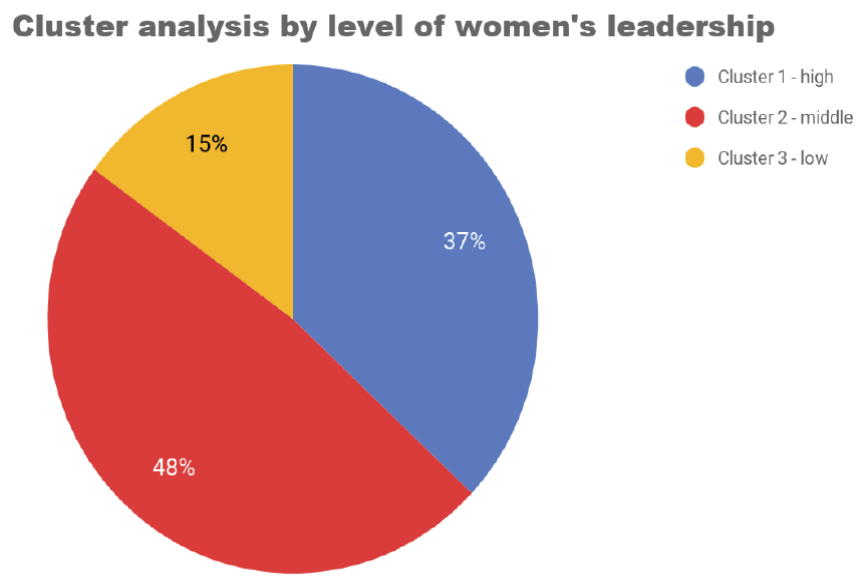

Figure 1: Distribution of professionally successful women scientists by groups according to the results of cluster analysis.

Further research was to identify personality traits that determine the professional success of women scientists with different levels of leadership skills.

Correlation analysis, Spearman's rank correlation, was used to establish the relationship between the level of leadership abilities and personal characteristics. Spearman's rank correlation index allowed to establish a relationship between the level of leadership and indicators of personal characteristics of the general sample and separately for each cluster. We analyzed the results for each cluster and identified certain differences.

Correlation analysis allowed us to see differences in indicators and characterize each group of women.

\section{DISCUSSION}

The process of success in psychology is considered one of the universal life values of the individual. The image of a successful person in the individual consciousness as a "model of the proper" regulates and directs actions in the construction of life strategies, professional and personal self-determination, and the choice of style and lifestyle. The life paths of successful women scientists are very diverse. By looking at the interactions between lifestyles, professional status, and contributions to science, one can explore the factors that have influenced the successful careers of women scientists. Using the example of prominent women scientists, Spanish researchers have identified the factors that influenced a successful career: family support, the novelty of the scientific field, the availability of good mentors during their careers, and certain periods of life spent abroad. The analysis of professional ways of the researched women shows that to achieve professional success, the organization of the daily, household, and private life and other social opportunities are important [17]. This has been repeatedly noted in the studies of Morán M.J.B., Echeverría I. D., Turrado T. F., Portolés C. M.

Let's review the professional success and leadership skills of women scientists in existing research to determine the place of our results in the existing research in this area and identify concordances and inconsistencies.

In our understanding, women's leadership is holistic and purposeful development of the individual in various aspects with the priorities of professional selfrealization, self-realization, personal independence, and success in life. However, there are several inconsistencies in various aspects of the analysis of the process of success by women leaders. These contradictions allow us to formulate another problem: is there a relationship between the professional success of women scientists and leadership skills.

Taking into account the results of our empirical study, let us discuss the results we have received and existing scientific research in the field of professionally successful women scientists in the context of forced leadership.

It is clear that in business life, one can see different types of women, and they all organize their behavior differently to perform management activities. Each of them may have problems that need to be understood to investigate them, as noted by M. Kathryn Bartol, C. David Martin [15]. To understand the personal characteristics and behavior of women who hold leadership positions in educational institutions, we studied three groups of studied women scientists, which we identified. 
Table 2: The Ratio of Personality Indicators and the Level of Leadership of Professionally Successful Women Scientists

\begin{tabular}{|c|c|c|c|}
\hline \multirow[t]{2}{*}{ Personal traits } & \multicolumn{3}{|c|}{ Level of leadership skills } \\
\hline & Cluster 1 (n-) & Cluster 2 (n-) & Cluster 3 (n-) \\
\hline $\begin{array}{l}\text { General indicator of } \\
\text { meaningfulness of life }\end{array}$ & 0 & & $\begin{array}{c}0.539^{*} \\
-0.517^{*} \\
0.105\end{array}$ \\
\hline Goals in life & $\begin{array}{c}0 \\
0.457^{*}\end{array}$ & $-0.507^{\star *}$ & $-0.943^{* *}$ \\
\hline Process of life & 0 & & $\begin{array}{c}0.490^{*} \\
-0.384 \\
0.949^{\star *}\end{array}$ \\
\hline Productivity of life & $0.593^{* *}$ & $\begin{array}{c}0 \\
0.480^{*}\end{array}$ & 0.316 \\
\hline Locus of control - Ego & 0 & & $\begin{array}{c}0.515^{\star} \\
-0.426^{*} \\
0.056\end{array}$ \\
\hline Locus of control - life & 0 & & $\begin{array}{c}0.406 \\
-0.638^{* *} \\
0.105\end{array}$ \\
\hline Motivation for success & 0 & & $\begin{array}{l}0.482^{*} \\
0.202 \\
0.632\end{array}$ \\
\hline Volitional self-regulation & 0 & & $\begin{array}{c}0.042 \\
-0.457^{*} \\
-0.472^{*}\end{array}$ \\
\hline Persistence & 0 & & $\begin{array}{c}0.018 \\
0.425^{*} \\
-0.316\end{array}$ \\
\hline Self-command & 0 & & $\begin{array}{c}0.003 \\
-0.447^{*} \\
-0.816^{* *}\end{array}$ \\
\hline Need for approval & 0 & & $\begin{array}{l}0.484^{*} \\
-0.159 \\
-0.056\end{array}$ \\
\hline
\end{tabular}

Note: ${ }^{*} p \leq 0.005,{ }^{* *} p \leq 0.001$

The first group of women with a high level of leadership skills is characterized by a high level of a meaningful life; they have life objectives and intentions, perceive their lives as interesting, rich, and productive. Women interviewed from this group believe that they can control their lives and the lives of others; they have a high motivation to succeed. Although they know what they are and what to do, they still focus on the approval of others. It is these personality traits that determine the realization of their leadership abilities and enable them to succeed. The results of correlation analysis show that women with high leadership abilities are not always emotionally stable; they can afford not to restrain emotions in stressful situations.
There is a negative correlation in the group of subjects with an average level of leadership skills as concerns many indicators. However, the correlations obtained show that a decrease in the level of leadership increases the level of general meaning in life, goals in life, life's performance, locus of life control, and volitional self-regulation. These are unexpected results for us, which need further analysis in the future.

Only persistence is positively correlated with leadership skills. It can be assumed that in this group, women succeed by combining leadership skills and perseverance; the lack of leadership qualities is compensated by strong-willed self-regulation, attempts 
to control life, setting professional goals, and selfcontrol. Under certain life circumstances, they are motivated to succeed, but they do not need the approval of others. They are generally always focused on meeting their own needs and achieving goals. As a result, the general level of meaningfulness of life in women from the second group increases in accordance with the decrease in the level of leadership skills.

According to the results of correlation analysis of the third group, the following results were obtained. The level of leadership is negatively correlated with the scale "goals in life", "self-control", and "volitional selfregulation", positively correlated with the scale "life process". As the level of leadership increases, the indicator of the process of life increases, which means that the subject characterizes the process of her life as interesting, emotionally rich, and full of meaning. But today, it can also characterize a hedonist living style.

As the level of leadership decreases, the indicators of "goals in life", "self-control", and "volitional selfregulation" increase, by this analysis, we can assume that the subjects of the 3 groups set good goals in life and succeed not due to leadership qualities but due to emotional stability, good self-control, inner peace in difficult situations, etc. However, the desire for constant self-control, excessive conscious restriction of spontaneity can lead to increased internal tension, the predominance of constant anxiety, and fatigue.

In groups of women with medium and low leadership skills, there is a tendency to increase selfcontrol and volitional self-regulation. The conclusion is that the main determinants of achieving professional success in these women are the focus on real-life circumstances, a high level of development of the emotional and volitional sphere, which is expressed in persistence, volitional self-regulation, self-control in difficult situations, emotional stability, and more. Selfconfidence brings freedom from fear of the unknown, increases the willingness to perceive the new, adaptable. In general, according to the authors, the most important characteristic of a leader is a high level of adaptability: the ability to understand what actions or approaches are needed in a given situation and then act accordingly. According to recent research, the ability to adapt has been extremely important during the crisis for the organizational success of women leaders in higher education [18].

Analysis of the results of empirical research shows that a high level of leadership skills really determines the professional success of women $(37 \%)$. But the other $63 \%$ have other determinants of professional success. Our research suggests that women who have achieved professional success, not on the basis of potential leadership skills, form a socially determined personal quality - forced leadership, which we can see as a mechanism for adapting the social environment and compensate for the lack of sufficient leadership skills. Forced leadership is a socio-psychological phenomenon based on the ability to adapt to living conditions in situations that require a person to choose activities against their own individual psychological characteristics, namely to become a leader, cultivate traits inherent in a true leader. In certain life circumstances, forced leadership becomes a way of survival.

Let's try to reveal the psychological mechanism of forced leadership. In our opinion, it is based on changing the image of "Self" of women who potentially have a low level of leadership skills, but various life circumstances and other social factors stimulate the release and use of internal psychological resources to overcome unnecessary emotions, stereotypes, fear, insecurity, etc. Women scientists are forced to change their own image of "Self" and constantly respond to it by directing their own psychological forces to selfdevelopment, learning, and professional activity. From a psychological point of view, it is a complex internal work through which women can achieve significant professional success but also have personal problems. The subjective image of a "successful personality" is a substructure of the "Self-concept", so women who have achieved significant results in order to adapt to a new situation, in the future experience a need to completely change their "Self-concept", bringing it in line with new achievements and the group's attitude towards itself.

In the context of our research, one of the interesting and little-studied problems of women's leadership is related to relationships with colleagues and support for women who are progressing in their careers. Using the personal stories of women leaders, Allen and Flood [19] note in their study that many women in leadership positions in academia are not prepared for a lack of support and camaraderie from colleagues. Lack of such support, work conflicts, family troubles create barriers to professional success. Thomas, S. notes the need to create strong, consistent institutional support to improve and accelerate women's progress in the higher echelons of academic governance. According to the author, this will help shape the future of higher education [20]. 
Our results are to some extent consistent with the research of $\mathrm{R}$. Cialdini that the professional success of a leader is determined by his ability to adapt his style to the needs of the group. So, considering the issue of effective leadership, R. Cialdini notes that if leaders adapt their style to the group's needs, they can act effectively. The author pays special attention to the fact that there are "some leaders who are effective not because they change themselves, but because they are able to transform the group and inspire it to achieve their own goals" [21].

T. Bendas adheres to approximately the same opinion in her studies [22-25]: in order to become a leader, you must first be selected to match the qualities of the individual to the qualities most valuable to the group. Then the group itself, reinforcing a certain behavior of the leader, contributes to the formation of personality traits that are especially in demand by the group. The more successfully the leader fulfills his/her role, the faster this process will go. At the heart of the female model of leadership, according to Bendas, is the principle of complementarity, additionality, vacuum [22]. She argues that her proposed model is described by referents such as female gender, young age, high levels of femininity and subordination, as well as low levels of competitiveness, aggression, and sexuality [24].

T.V. Bendas suggest that women leaders are most effective in solving leadership tasks related to human relations, while male leaders are more successful in solving technical problems $[23,25]$. And this correlates with the data on the most important characteristic of a woman leader, according to the authors, is a high level of adaptability: the ability to understand what actions or approaches are needed in a given situation and then act accordingly.

Sociologists and psychologists have made significant efforts to study the phenomenon of leadership, among them: K. Handy, D. McGregor, A. Philly, R. House, K. Levin, R. Lipit, M. Harris, J. French, A. Corman, E. Fleischman, and others. Theories exchange and transactional analysis also figure prominently among studies on leadership. J. Homans, D. March, G.A. Simon, J. Thibaut, G. Kelly, K. Jergen see the leader as a person who feels the needs and desires of his followers and suggests ways to implement them. Here lies the emphasis on the emotional side of the process. A leader can be focused on solving real problems, achieving certain goals, and giving paramount importance to relationships with others.
In this regard, a number of studies are devoted to the problem of developing personal qualities of women (professional mobility, the impact of the collective environment on pedagogical success) for future professional advancement $[26,27]$. Also, in the area, our research has shown that the leadership abilities of professionally successful women scientists correlate with such qualities as perseverance and volitional selfregulation. The ability to set professional goals, selfcontrol, and motivation for success, do not need the approval of others, and focus on self-satisfaction.

So, by the logic of our study, the "subjective image" of a successful person is one of the variants of the ideal self. This professional image reflects the idea of success in the public consciousness. From the standpoint of the theory of socio-psychological adaptation of the individual, the subjective image of a "successful woman scientist" can be correlated with situational role models. Women face different problems at various stages of building a successful career, and each requires a separate role model. Effective roleplaying helps a woman overcome difficult life and professional situations, maintain career mobility, be successful in the profession, and achieve a healthy work-life balance [28].

So, the theory of gender selection of leaders, developed by J. Bowman and S. Sutton, arises from the assumption that people in private and corporate milieu make different demands on leaders of different sexes. We believe that the identified features of women scientists with different levels of leadership abilities can specify the requirements for leaders depending on their gender. These requirements are as follows for women: to get a leadership position, a woman must demonstrate much greater competence. Because it is difficult, there are not many recognized women leaders $[26,27]$.

In his writings, Alice Eagle describes the path to leadership not as a path to a ceiling to which there is no access but rather as a labyrinth where one has to navigate and find ways out. This new metaphor speaks to the need for several models of leadership and the recognition that a woman leader can do it differently than a man. Navigation in the maze will be easier if women learn their strengths and advantages [13].

Thus we see that the leadership of female scientists is a component of their success. We find confirmation of this in a study of Eric A. Landis, D. Hill, and Maurice R. Harvey [29]. Leadership is considered one of the 
most important components of an organization's success. For example, McCobby concluded that corporate need to survive and thrive in a world of increasing competition, technological advancement, changing government regulations, and changes in attitudes toward employees requires "a higher level of leadership than ever before." When organizations are changing, their organizational leadership must be adequate to address the problem.

An effective and successful leader inspires, motivates, and directs activities to achieve group and organizational goals despite many different leadership styles. Conversely, an ineffective, unsuccessful leader does not contribute to organizational progress and may actually hinder the achievement of organizational goals. According to Rose Ngozi Amanchukwu, Gloria Jones Stanley, and Nwachukwu Prince Ololube, effective leadership is a product of the heart, and a successful leader must be insightful, passionate, creative, flexible, inspired, innovative, bold, creative, experimental, and initiate change [30].

In the business community, there are many different kinds of obstacles that can prevent a woman from realizing her goals in the profession. At the same time, today, many women are making progress in their professional careers, so it is important to understand what socio-psychological factors contribute to this process. We hope that our research on forced leadership will help better understand women scientists' psychology, their professional qualities, personal problems, and the path to success.

Realization of the professional opportunities for the woman scientist demands considerable psychological resources, which are a basis for achieving the set purpose. Successful women always attract attention, are treated with respect, support, admiration, and even adoration. At the same time, modern research shows that internal contradictions characterize the semantics of perception of the image of a successful woman scientist: the image of a successful woman scientist is perceived as respectable, but not always, and not in everyone causes positive perception and sympathy. Research shows that women in higher education worldwide face several challenges that still persist instability of women scientists in management careers sometimes prevents them from achieving equal representation in management positions [31-34].

In recent years, a lot of research has appeared in the world scientific space, which examines the problem of stereotypical views on women's behavior that prevent them from striving for high-ranking leadership positions in higher education [35-38].

But it does not always depend on stereotypes. In his study, Krause, S.F., showed that stereotypical views of women had little effect on women's successful careers in higher education, with preference given to more personal qualities and the ability to manage people. The ways in which women often go to power force us to rethink the structure of leadership and pay attention to psychological and cultural factors [39].

Much of the existing research on women's leadership in higher education does not yet adequately shed light on the ways and personal preconditions through which women scientists achieve professional success. It is not always possible to understand how a seemingly weak, calm, friendly woman scientist can take responsibility, manage people, make constructive decisions, and withstand psychological stress. As a result, the issue of women's leadership will remain relevant and in demand for a long time to come.

Considering the results of our research that professionally successful women scientists are forced to take the position of a forceful leader, we have a question: what are the main factors that motivate women scientists to become leaders. Referring to research where we find one of the answers to this question. McGrath Cohoon, Vivek Wadhwa, Lesa Mitchell highlighted the main factors that motivate women to become entrepreneurial leaders. In general, women who want to become leaders are motivated primarily by five financial and psychological factors, including:

1. The desire to increase their wealth.

2. The desire to implement business ideas that they have

3. Attractiveness of startup culture.

4. A long-standing desire to have one's own company.

5. They do not like to work for someone else [14].

K. Bartol and D. Martin showed that a woman leader in the business world of men and in general, being in a men's group, performs one of four informal roles:

1) "mother" - she is expected to provide emotional support, not business activity; 
2) "temptress" for the boss, which causes outrage among male colleagues;

3) "toy, mascot" - a pretty, but not a businesswoman who brings good luck;

4) "iron lady", which has a non-female rigidity, resulting in the most isolation from the group [15].

A woman scientist, being in a leading position, behaves according to her own self-concept in any situation. Her behavior depends on how she perceives herself. Adequate awareness of the dominant components of the self-concept allows a woman leader to more clearly implement the basic functions of management: planning and control, decision-making and conflict resolution, work incentives, and more. According to research by Bachtold and Werner, women scientists are more serious, confident, dominant, intelligent, radical, and adventurous than women in the general population, but less sociable, often groupdependent, and sensitive to external factors [40].

Summarizing the above, we can conclude that the problem of achieving professional success by women scientists, in general, is the most important in terms of general problems of personality, its development, and social adaptation. The phenomenon of forced leadership of professionally successful women scientists is gaining real importance in connection with the realization of scientific research in the 21 st century in various areas of human life and activities, such as, health, technology, relationships between people, and the sphere of education. Where women scientists hold leadership positions and make managerial decisions $[41,42]$.

Modern society encourages everyone to become active, creative, and competitive without exception, but there are not many real leaders. One of the reasons for the lack of trained leaders in higher education is that few women can take on such critical roles. Analyzing the reference sources on leadership gives us reason to believe that women who have potential leadership skills are much more likely to be successful. In many studies, leadership is seen as the key to professional success and career growth. This is the basis of our assumption that the professional success of women scientists depends on the level of their potential leadership skills.

The results of our study confirm this, and at the same time, allow us to assert that potential leadership abilities are not always the psychological basis of a woman's professional success. Difficult life circumstances and other social factors can stimulate the work of internal psychological resources to achieve professional success and cultivate leadership qualities for management activities. In such situations, the phenomenon of forced female leadership, which is characteristic of modern democratic society, is clearly manifested.

\section{CONCLUSION}

The study was performed within the research topic "Peculiarities of self-image detection in the context of lifelong learning", which is being worked on by research and teaching staff of the Faculty of Psychology and Special Education of Oles Honchar Dnipro National University.

The results of the study allowed us to consider for the first time the phenomenon of forced leadership in women scientists, define it, try to reveal its psychological mechanism, expand the scientific understanding of women's leadership in higher education, and show the relationship between leadership skills and professional success of women scientists.

Research has shown that there is a link between women's professional performance, leadership skills, and personal characteristics. But in general, it is very difficult to predict how successful a woman will be, even on the basis of information about her leadership abilities and personal characteristics. In our opinion, it all depends on life circumstances that can "provoke" the development of any personal qualities in women to achieve professional success.

A successful woman will always raise questions and demands from others certain changes in their attitude to her. The analysis of gender features of the image of success and motivation to achieve success shows gender differences in perceptions of success, which are manifested primarily in the fact of greater internal conflict of the phenomenon of "female success". The internal contradiction of "female success" by researchers is due to the fact that the image of "success" is semantically related to masculinity, male type of self-realization, a departure from femininity, manifested in specific intrapersonal gender conflicts of women seeking to achieve social (professional) success. At the same time, studies of various aspects of male and female self-realization reflect the rapid pace of transformation of modern social ideas about the criteria and images of "male" and "female" success. 
As a result, in recent years, the Nordic countries have achieved a minimal gender gap in the areas of economic participation, education, health, and empowerment. Norway, Iceland, and Finland have achieved the highest ratings in these matters. Even in Saudi Arabia, one of the most controversial countries in terms of its low gender gap, the government has implemented many reforms that are expected to directly impact women's empowerment, including in higher education $[43,44]$.

Summarizing the above, we conclude that problem the professional success of women scientists and the socio-psychological foundations of woman leadership, in general, is important from the point of view of general problems of the personality, its development, and adaptability. At the same time, with our research, we drew attention to the existing contradictions in the aspect of the correlation between the professional success of women scientists and their potential leadership abilities. It is revealed that in modern society, there is a phenomenon of forced leadership, when a woman, without potential leadership qualities, is able to demonstrate effective leadership in a group and achieve significant success in management activities.

One of the important issues that are subject to further research is the impact of forced leadership on women scientists' quality of management decisions in educational activities, on their psychological health, and family life.

We believe that further research on the phenomenon of forced leadership among women who have achieved professional success has a high social significance and scientific potential. In the context of the researched problem, we have already started investigating the attitude of men to professionally successful women, wherein it is planned to investigate the peculiarities of the perception of professionally successful women by men depending on their normative attitudes.

The ambiguity and inconsistency of the results of our study lead to a high understanding level of leadership qualities that do not always determine the professional success of women scientists. One-third of the women studied the socio-psychological determinants of success are complex life circumstances and personal characteristics associated with volitional qualities.

\section{ACKNOWLEDGEMENT}

We would like to thank the women leaders of the Oles Honchar Dnipro National University. They participated in the study and the co-authors for organizing and conducting the study in various universities of Ukraine.

The authors would like to express gratitude to the editors and the anonymous reviewers for their encouraging and constructive comments on this paper.

\section{SUPPLEMENTAL MATERIALS}

The supplemental materials can be downloaded from the journal website along with the article.

\section{REFERENCES}

[1] Shultz KG. The impact of leadership development programming on the career pathways of females in higher education 2019.

[2] Madsen SR. Women and leadership in higher education: Learning and advancement in leadership programs. Advances in Developing Human Resources 2012; 14(1): 3-10. https://doi.org/10.1177/1523422311429668

[3] Chanana K. Women and leadership: Strategies of gender inclusion in institutions of higher education in India. In Strategies for Supporting Inclusion and Diversity in the Academy. Palgrave Macmillan, Cham 2020; pp. 141-162.

[4] Oleksiyenko OH, Martsyniak-Dorosh OM, Mishyn SV, Buryanovatiy OM, Yakymchuk BA. Impact of Convergence of Smart-Technology as Compared to Traditional Methodological Tools on Fostering Cognitive Aspects of Leadership Competencies in the Process of Vocational Training of Students. Journal of Intellectual Disability - Diagnosis and Treatment 2019; 7(1): 1-8.

https://doi.org/10.6000/2292-2598.2019.07.01.1

[5] Alexandra Symonds MD. Neurotic Dependency in Successful Women. Journal of American Academy of Psychoanalysis 1976; 4(1): 95-103.

https://doi.org/10.1521/jaap.1.1976.4.1.95

[6] Clance PR, Imes S. The Imposter Phenomenon in High Achieving Women: Dynamics and Therapeutic Intervention. Psychotherapy Theory, Research and Practice Volume 1978, 15(3): 241-247. https://doi.org/10.1037/h0086006

[7] Reavley MA, Lituchy TR. Successful women entrepreneurs: a six-country analysis of self-reported determinants of success more than just dollars and cents. Int. J. Entrepreneurship and Small Business 2008; 5(3/4): 272-296.

[8] Globally the Share of Women in Senior Management is Increasing Incrementally. Aug 11, $2020 . \quad$ URL: [https://www.catalyst.org/research/women-in-management/]

[9] Social psychology: key ideas / R Baron, D Byrne, B Johnson. Spb. Piter 2003; 428.

[10] Ngunjiri FW, Hernandez KAC. Problematizing authentic leadership: A collaborative autoethnography of immigrant women of color leaders in higher education. Advances in Developing Human Resources 2017; 19(4): 393-406. https://doi.org/10.1177/1523422317728735

[11] Moodly AL, Toni N. Do institutional cultures serve as impediments for women's advancement towards leadership in South African higher education? South African Journal of Higher Education 2019; 33(3): 176-191.

[12] Wheaton MM, Kezar A. Interlocking systems of oppression: Women navigating higher education leadership. In Research Anthology on Challenges for Women in Leadership Roles. IGI Global 2021; pp. 766-788. 
[13] Eagly Alice H. Sex differences in social behavior: Comparing social role theory and evolutionary psychology. American Psychologist 1997; 52(12): 1380-3.

https://doi.org/10.1037/0003-066X.52.12.1380

[14] The Anatomy of an Entrepreneur Are Successful Women Entrepreneurs Different From Men? J McGrath Cohoon, Vivek Wadhwa Lesa Mitchell 2010.

[15] Bartol Kathryn M, Martin David C. Management / M. Kathryn Bartol, C. David Martin. - Div: McGraw Hill, 1994; p. 832.

[16] Kapranova MV, Kostyrya SS. Psychological features of professional career of women managers of business structures. Modern social psychology: theoretical approaches and applied research 2011; 3(12): 92-101.

[17] Morán MJB, Echeverría ID, Turrado TF, Portolés CM. Life paths of successful women scientists in Spain. Géneros 2014; 3(1): 351-372.

[18] Tevis TL, Pifer M, Baker VL. Women Higher Education Administrators: Approaches to Leadership in Times of Crisis. In Women and Leadership in Higher Education During Global Crises. IGI Global 2021; pp. 36-54.

[19] Allen TG, Flood CT. The Experiences of Women in Higher Education: Who Knew There Wasn't a Sisterhood?. Leadership and Research in Education 2018; 4: 10-27.

[20] Thomas S. Women in Higher Education Administration Leadership and the Role of Institutional Support. In Research Anthology on Challenges for Women in Leadership Roles. IGI Global 2021; 282-297.

[21] Chaldini R, Kenrick D, Neuberg S. Social psychology. Understand others to understand yourself. Spb 2002; 256.

[22] Bendas TV. Gender psychology: teaching. textbook, SPb: Peter 2009; 430.

[23] Bendas TV. Gender psychology of leadership. Orenburg: IPK OGU 2000; 167

[24] Bendas TV. Psychology of leadership: gender and ethnic aspects. SPb 2002; 56 .

[25] Bendas TV. Prospects for the development of gender psychology of leadership in the world of modern scientific trends. Modern social psychology: theoretical approaches and applied research 2011; 3(12): 85-92.

[26] Nurzhanbayeva Z, Aidarov B, Baltabekova A, Makhmudov G, Kamalov Y, Seisen N. Semantic Guidelines and Conceptual Basis of a Social Education Teacher Professional Mobility in the Pedagogical Science. Journal of Intellectual Disability - Diagnosis and Treatment 2020; 8(3): 560-566.

https://doi.org/10.6000/2292-2598.2020.08.03.33

[27] Syzdykbayeva AD, Mambetalina AS, Nuradinov AS, Kurmanbekova MB, Kabylbekova ZB. Collaborative Environment as a Means of Forming Success of a Future Teacher of Elementary Classes in Project Activity. Journal of Intellectual Disability - Diagnosis and Treatment 2020; 8(3): 370-376. https://doi.org/10.6000/2292-2598.2020.08.03.13

[28] Didenkulova I, Avellis G. Role Models for Mobile Women Scientists. In EGU General Assembly Conference Abstracts 2020; 15490.

[29] Eric A. Landis, Deborah Hill, Maurice R. Harvey A Synthesis of Leadership Theories and Styles 100 Journal of Management Policy and Practice 2014; 15(2).
[30] Amanchukwu RN, Stanley GJ, Ololube NP. Review of Leadership Theories, Principles and Styles and Their Relevance to Educational Management 2015; 5(1): 6-14. https://doi.org/10.5923/j.mm.20150501.02

[31] Abalkhail JM. Women and leadership: Challenges and opportunities in Saudi higher education. Career Development International 2017.

https://doi.org/10.1108/CDI-03-2016-0029

[32] Burkinshaw $\mathrm{P}$, White K. Fixing the women or fixing universities: Women in HE leadership. Administrative Sciences 2017; 7(3): 30.

https://doi.org/10.3390/admsci7030030

[33] Aiston SJ, Yang Z. Absent data, absent women: Gender and higher education leadership. Policy Futures in Education 2017; 15(3): 262-274.

https://doi.org/10.1177/1478210317716298

[34] Johnson HL. Pipelines, pathways, and institutional leadership: An update on the status of women in higher education 2017.

[35] Chin JL, Ladha A, Li V. Women's leadership within a global perspective. In: C. B Travis, J. W. White, A. Rutherford, W. S Williams, S. L. Cook, \& K. F. Wyche (Eds.), APA handbooks in psychology $\otimes$. APA handbook of the psychology of women: Perspectives on women's private and public lives. American Psychological Association 2018; pp. 565-581. https://doi.org/10.1037/0000060-030

[36] Rini M. Where Women Scientists Are the Majority. Physics 2021; 14: 35 https://doi.org/10.1103/Physics.14.35

[37] Chapple A, Ziebland S. Challenging explanations for the lack of senior women in science? Reflections from successful women scientists at an elite British University. International Journal of Gender, Science and Technology 2018; 9(3): 298-315.

[38] Pietri ES, Johnson IR, Ozgumus E, Young Al. Maybe she is relatable: Increasing women's awareness of gender bias encourages their identification with women scientists. Psychology of Women Quarterly 2018; 42(2): 192-219. https://doi.org/10.1177/0361684317752643

[39] Moodly AL, Toni NM. Re-imagining higher education leadershipin conversation with South African female deputy vicechancellors 2017. https://doi.org/10.18820/2519593X/pie.v35i2.12

[40] Bachtold LM, Werner EE. Personality characteristics of women scientists. Psychological Reports 1972; 31(2): 391-396. https://doi.org/10.2466/pr0.1972.31.2.391

[41] Longman KA. perspectives on women's higher education leadership from around the world 2018.

[42] Alotaibi FT. Saudi Women and Leadership: Empowering Women as Leaders in Higher Education Institutions. Open Journal of Leadership 2020; 9(03): 156.

[43] Fetterolf J, Eagly $\mathrm{AH}$. Do young women expect gender equality in their future lives? An answer from a possible selves experiment. Sex Roles 2011; 65(1-2): 83-93. https://doi.org/10.1007/s11199-011-9981-9

[44] Moodly A, Toni NM. Accessing higher education leadership: Towards a framework for women's professional development. South African Journal of Higher Education 2017; 31(3): 138-153. https://doi.org/10.208535/31-3-917

\section{https://doi.org/10.6000/2292-2598.2021.09.04.7}

(C) 2021 Olha et al.; Licensee Lifescience Global.

This is an open access article licensed under the terms of the Creative Commons Attribution Non-Commercial License (http://creativecommons.org/licenses/by-nc/3.0/) which permits unrestricted, non-commercial use, distribution and reproduction in any medium, provided the work is properly cited. 